\title{
Breaking the isolation: A study of university teachers' collective development
}

\author{
Jeanna Wennerberg and Cormac McGrath
}

\begin{abstract}
Today many university teachers attend competency development courses as individuals. In this paper we consider collegial and collective competency development. We examine what role collegial peer review could play in developing the Scholarship of Teaching and Learning for university teachers. The paper is based on a case study that explores how a group of university teachers experienced collegial development and peer review. Based on the teachers' account, we identify how the activity helped them break the isolation they experienced at their department, enabled them to navigate the landscape of different courses and strengthened their roles as teacher, e.g., through collaboration with colleagues. We also present some frictions and tensions that were reported. Based on the case study, we propose that professional development in academia could benefit from acknowledging collegial peer review as an output in its own right.
\end{abstract}

Keywords: collegial peer review; continual professional development; critical friend; formative peer review; peer review of teaching; Scholarship of Teaching and Learning

Received 8 April 2021; revised version received 29 October 2021; accepted 3 December 2021. Corresponding author: Jeanna Wennerberg, Stockholm University (jeanna.wennerberg@su.se).

\section{Introduction}

Formative and collegial approaches to peer review that are 'used to amplify the best aspects of one another's teaching and bring the best aspects of other's teaching into our own' (Fileborn et al., 2020, p. 12) may work very well in contexts where the teachers' autonomy regarding teaching is high. However, the Scholarship of Teaching and Learning (SoTL) literature identifies a need for continual professional development for university teachers with a focus on situated practice in departmental contexts (Geertsema, 2016; Huber \& Hutchings, 2006; Hutchings, Huber \& Ciccone, 2011; Myatt et al., 2018; Tierney et al., 2020). A central idea in SoTL is dissemination and peer review, where colleagues investigate and document 
different elements of their own practice, as well as make those practices public for their peers (Boyer, 1990; Kreber, 2002; Trigwell \& Shale, 2004). However, since situated teaching practice is collective by nature, development may also be dependent on collegial collaboration. Our experiences as educational developers from Nordic and European contexts suggest that peer review of teaching is rare among higher education educators. Culturally, in the Nordic region, university teachers, once they have tenure, are not subject to any forms of externally mandated peer review or teacher evaluation (de Lange \& Wittek, 2020). Similar sentiments relating to higher education instructors' professional development have been identified in other contexts too (Poole et al., 2019). Academic developers engage, for the most part, in interaction with individual scholars, as opposed to working with groups of colleagues from the same department (McGrath, 2020). We therefore see the need for the academic developer community to broaden the scope of their traditional work to include more collective ways of interacting with university teachers. Such practices may contribute to more contextual and continual professional development in higher education. In this paper, we present an example of collegial faculty development, here called collegial peer review (CPR) that we undertook with a group of higher education teachers and examine the outcome of participating in such a programme.

This process of individual merit and course-taking mimics and continues the tradition of formal education, where many students, and subsequently academics, form their own educational trajectories (McGrath, 2020 ). Moreover, in many settings, promotion to higher academic rank is dependent on individual research and teaching merits acquired during the course of an academic career. As such, academic development credit may be seen as a form of currency that can be traded for other items, for example, promotion, influence and maybe even a higher salary.

In contrast to the individual trajectories, more collective models of academic development work are slowly emerging (Gosling, 2014). This suggests that academics, at least in some cases, wish to learn in contextual settings together with other colleagues (Söderhjelm et al., 2018; van der Rijst, Baggen, \& Sjoer, 2019).

\section{Background}

In the 1980s, teaching portfolios grew popular in the US, containing, among other things, documentation of teaching skills and reports of colleagues' classroom observations. Peer review of teaching (hereafter peer review) has subsequently evolved, and considerable research has been conducted to identify key features of 
sustainable peer review practice (Bernstein, 2008). Portfolios continue to be a prominent aspect in teacher evaluations (Bernstein, 2008). Since the 1990s, tensions between summative and formative forms of peer review have been debated, where the summative forms of peer review may be said to follow more managerial approaches to evaluating teacher practices (Centra, 1993). When viewing peer review as a developmental practice, peers are considered to be appropriate interlocutors when discussing teaching practice and may provide key critical insights into shared experiences (Sell \& Chism, 1988).

While much of the writing and research on peer review overlap conceptually, there is a distinction between peer observation of teaching and peer review of teaching (Engin, 2016), where teaching observation does not necessarily include any follow-up discussion between the participating academics or any evaluation of the teaching performance. Peer observation has often been used as a top-down model for evaluation, to ensure quality of teaching on an individual basis. Undergoing peer observation of teaching is an annual requirement in some higher education settings worldwide (Byrne, Brown, \& Challen, 2010). Peer observation holds potential, as Bell and Thomson postulate: 'when academics observe real teaching situations, that observation prompts reflection on teaching, which in turn provides an opportunity for conceptual expansion about learning and teaching' (2018, p. 277).

Peer review of teaching, which includes colleagues engaging in exploratory dialogue about teaching practices and analysing different areas of practice, has, in recent years, become more commonly used as a tool for structured peer development in institutional settings (Donnelly, 2007; Gosling, 2014). Esterhazy et al. (2021) identify collegial faculty development as an umbrella concept, revolving around different elements of collegial work in higher education, where university teachers observe each other during teaching and use these observations to generate reflective discussions around collaborative development on their teaching practices. Previous research has identified several positive outcomes of peer review, including the discovery of new ways of talking about teaching, increased confidence and emerging self-efficacy, the development of teaching skills and stronger collegiality, as well as mitigating feelings of isolation (e.g., Bell \& Cooper, 2013; Centra, 1993; de Lange \& Wittek, 2018; Donnelly, 2007; Engin, 2016; Hendry, Bell, \& Thomson, 2014; Hutchings, 1996; Hutchings, 1995; Sell \& Chism, 1988; Shortland, 2010). However, research on peer review also acknowledges some drawbacks (Gosling, 2014) regarding the subjective nature of what constitutes good teaching. For example, Esterhazy et al. (2021) suggest that a teaching review process in which faculty are merely informed about how they are rated on various quality criteria rather than receiving formative feedback is less likely to contribute to the development of teaching quality. Other drawbacks include staff reluctance to 
engage in peer review and the risk of engaging in peer review only to comply with institutional policies, focusing too much on what is visible in the classroom, and the underlying power dynamic in the feedback situation, which might cause observed-teacher anxiety.

One form of peer review that inspired the present case study is Critical Friend. The Critical Friend concept originally related to dialogue between academic colleagues involved in research projects who were trying to identify and analyse troublesome aspects of research (Dahlgren et al., 2006). Critical Friend, as a form of peer review, has subsequently been revitalized; for example, both Handal (1999, 2007) and Dahlgren et al. (2006) suggest that Critical Friend is useful for reflection and continuous professional development for university teachers. In much of the Critical Friend literature the focus is on the relationship between peers; friendship and mutual trust are often evoked as key concepts (Baskerville \& Goldblatt, 2009; Dahlgren et al., 2006; Handal, 1999, 2007; Kember et al., 1997). The emphasis on trust is key when viewing Critical Friends in the context of other observation activities (Costa \& Kallick, 1993) but trust has also been identified in relation to collegial faculty development initiatives (Esterhazy et al., 2021). Critical Friend has received increasing attention throughout the years, in particular in the Nordic academic developer community; it is used in other professional settings, too, for example in the continued professional development of librarians (Özek, Edgren, \& Jandér, 2012), in school and teacher education (Costa \& Kallick, 1993; Kember et al., 1997). Critical Friend is often conducted on a one-to-one basis. In this study we are more concerned with collegial practices. Chism et al. (2013) found in their metastudy on the impact of education development that collegial peer review had an impact on participants' practices and to some extent on student learning. In a more recent study on collaborative interactions in teaching within cross-disciplinary peer-supervision groups, de Lange \& Wittek (2018) found that the participants 'gained new insights about teaching practices that resemble previous findings on peer-based feedback practices on teaching' (2018, p. 337). Bolander Laksov et al. (2020) found that team-based faculty development had several advantages, e.g., seeing problems from different perspectives and feeling support from the team members when questioned by peers. Given our expressed wish to explore collegial and collective practices and developments, we therefore designed a collegial form of peer review.

\section{Introduction to the collegial peer review (CPR) model}

In the case study that we present in this paper, academic developers (the authors) worked closely with the Director of Studies to develop the material and plan and 
organize the program. With the broader collegial faculty development literature in mind, we devised a number of CPR activities ${ }^{1}$ with the explicit purpose of engaging academic staff in collective and formative collegial peer review. The purpose of these activities was further to stimulate personal as well as institutional, or at least department-wide development (Braskamp \& Ory, 1994). The activities were designed to have 'a clear structure with agreed purposes, procedures, and outcomes involving suitable preparation, follow-through, and rules of confidentiality' (Donnelly, 2007, p. 127). The model implemented in our study was inspired by Gosling's (2014) 'collaborative model' in that it provided a non-managerial driven development environment with the aim to encourage critical reflection and peer scrutiny. The aim of collegial peer review is often to improve teaching through dialogue in a non-judgemental manner. The participants were asked to:

1. host a preparatory meeting with the teacher whose teaching will be observed, in order to establish a shared understanding of the purpose of the observation;

2. visit the teacher's lecture or seminar;

3. engage in a follow-up meeting involving feedback and shared dialogue concerning the teaching practice observed;

4. engage in a follow-up group discussion on teaching and learning practices.

In the preparatory meeting, participants are prompted to take notes and choose an aspect of his or her teaching practice for the colleague to review. Participants could choose between five different CPR activities (see the supplementary material via the link in the footnote).

\section{Context and respondents}

The context of our study is a department at one of Sweden's largest universities, with more than 30,000 students. The department in question, with a total staff of around 130, offers a number of proficiency courses in Swedish as a Foreign Language to international students and university staff, and the smaller unit where the study took place that offers these courses had 17 full-time teachers.

The teachers had previously expressed a desire to increase collegial collaboration around teaching. In cooperation with their leaders, who also granted time for participation, we designed and organized a number of CPRs aimed at enhancing in-depth collegial exchange regarding different aspects of teaching and student learning. In the study, the participants used different CPR activities and

\footnotetext{
${ }^{1}$ https://doi.org/10.17045/sthlmuni.12058332
} 
took part in regular group discussions of the observations and opportunities for development under the guidance of a discussion facilitator.

All 17 full-time teachers in this unit were invited to participate; 16 took part, 9 of whom were women. Their experience of working in a university varied between 1 and 30 years. The program was non-mandatory, with an opt-out possibility at any time. Even though no one opted out, after the project began, there was a difference in the number of peer review activities each participant engaged in. Participants were allocated approximately three hours for every CPR activity. Participating in the peer review program was meant to be open at least to others observing one's teaching. The participants were free to choose whoever they wanted to observe among the participating teachers.

\section{Data collection}

We conducted semi-structured, in-depth group interviews with all 16 respondents in groups of 4 to 6 respondents on three separate occasions during 2018. We also sent a survey to all respondents, enabling them to report reflections and comments that they might not want to share during the focus-group interviews. To engage the respondents in in-depth reflections about the outcome of the CPR activities, we approached the topic from three primary angles:

- questions related to choices of partnerships and choice of CPR activity, and related to the overall process of conducting the activities;

- questions related to insights and changes in practices that followed from the different activities;

- questions related to concerns the respondents may have had when or as a result of visiting one another.

The interviews lasted between 45 and 65 minutes and were later transcribed. Quotes from these interviews in Swedish were translated and are rendered here in English.

\section{Data analysis}

We adopted a qualitative content analysis of both the interview data and the open responses to the survey data (Elo \& Kyngäs, 2008; Hsieh \& Shannon, 2005) in order to understand how the participants experienced the collegial peer review activities. The data was analysed using an inductive, semantic content analysis approach (Elo \& Kyngäs, 2008). To begin with, we transcribed the group 
interviews. We also extracted the survey data, and then we read through the transcribed material as well as listening to the audio recordings several times in order to get familiarised with the data. While doing so, we independently took notes on recurring contents relating to the research questions throughout the data. We identified words and phrases up to a few sentences that relate to the same central meaning as units of analysis. The semantic approach of our study meant that the categories we created corresponded linguistically to content expressed in the data (McGrath et al., 2019a). We then discussed the categories together, in an attempt to organize the data as accurately as possible. An ongoing interpretation of the underlying significance of the categories was made, and the categories were subsequently redefined during the ongoing analysis. The different phases in qualitative content analysis described here involve an iterative process rather than a linear one, which is illustrated in the following steps below (Elo \& Kyngäs, 2008):

1. Familiarization: reading through the interview transcripts and the survey generated data to get a feel for the material; at this stage all data in the dataset are given equal consideration

2. Condensation: identifying meaning units and marking these for the purpose of further scrutiny; the size of the meaning units can vary.

3. Comparison: comparing the units with regard to similarities and differences

4. Grouping: allocating similar meaning units to the same category

5. Labelling: expressing the core meaning of the category; steps 3-6 are repeated in an iterative procedure within the research group to make sure that the similarities within and differences between categories are discerned and formulated in a distinct way.

\section{Findings}

This section presents the findings as five categories which emerged through the semantic analysis: Breaking the isolation; Navigating the landscape; Strengthening the role as a teacher; Further collaboration; and Frictions and tensions. 


\section{Breaking the Isolation}

Breaking the isolation is characterised by the respondents identifying that engaging in CPR activities mitigates the isolation they previously felt in their department. The respondents said that they sometimes feel alone in their teaching practice and within their department. Isolation was often involuntary, something that had evolved over a long period of time. Moreover, they reported that they did not perceive any requirements or opportunities to collaborate with colleagues regarding teaching; rather, it was left to them to initiate such opportunities. This meant that they were not required to collaborate with others, for example, by management; moreover, they reported that when they did collaborate with others, it was usually with the same people. The respondents reported that they usually worked on their own and only occasionally shared thoughts about their teaching with other colleagues. Often, such sharing emerged serendipitously; they shared thoughts with colleagues with whom they shared a room, even if this person did not teach the same course. Some teachers were using a syllabus that someone else had designed, which they argued was done in order to harmonise the experience for the students, but which also created fewer opportunities to engage in dialogue. However, the respondents reported that the $\mathrm{CPR}$ activities gave them an opportunity to break their isolation. This is illustrated by the two following quotes:

You work quite isolated. Even if you work within the same course, the different sub-courses are quite isolated from each other, so the [peer reviews] are after all a very good way to see, for your own sake, not just for the students, a bit of what is happening in the other courses.

And then for my part it is - maybe a little unprofessional, but for my part it was very much to break the isolation that I wanted to take part ... because you feel isolated and hardly talk to anyone because you are sitting on another floor, or maybe you are closed off in your room and sitting and working alone with what you do and so on.

In summary, breaking the isolation is characterised by the respondents acknowledging that teaching is quite often a solitary business involving involuntary isolation. There has been a strong desire to get rid of this isolation in the department, and the CPR activities helped in this regard.

\section{Navigating the landscape}

The respondents reported that the CPR activities, by way of structured observations, enabled them to navigate the landscape within their department. For some newly employed respondents it presented a first opportunity to gain a broader 
understanding of the scope of the work being done at the department and to be able to navigate in the myriad of interrelated courses offered. It also offered a chance to understand the level of different courses as well as the progression between interrelated courses. The respondents spoke about the advantage of becoming aware of how other courses related to their own courses, in terms of a better understanding of the students' pathways. Moreover, they reported on their experiences with different teaching techniques throughout the program, and also how to coordinate the content of the related courses in collaboration with the other teachers. The CPR activities helped them understand how the levels of knowledge and language proficiency in the related courses differed, as well as how students comprehended the course literature. They also reported that the CPR activities gave them an opportunity to reflect on how their own teaching practice aligned with that of their colleagues, as shown in the following two quotes:

I have been to visit XX, for example, and that's because she has a course for foreign staff and I gave the course before. I wanted to see where she set the bar for this course. That allows us to better coordinate courses. See which literature they use, where my students need to come in and so on.

In the course I teach, the students have said that 'the vocabulary course' was fun or demanding or difficult. And I thought, damn it! I should know more about that course. And many students in my preparatory course said the exam on the 'grammar course' was too difficult.

For others, especially the more experienced respondents, the CPR activities offered a chance to revisit their role as experienced teachers. It provided them with an opportunity to calibrate and get ideas about how to develop their own teaching, or certain aspects of their teaching, so that it would align with local expectations and ways of doing things. The CPR activities afforded the respondents an opportunity to observe different teachers' planning and teaching, enabling them to use the different experiences as a way of navigating existing practices at the department and to be exposed to different ways of teaching. This is shown in the two following quotes:

I saw what those teachers did. And I thought: 'Oh, I want to do this, too.' But I could also see what I usually do differently ... 'Why do I do that?' And then you start to question what you do yourself...

I observed another teacher who had the same course as me, and then I observed XX, who also had the same course. So, it was fun to see how we 
were all teaching almost the same, but a little differently. I feel that you can see from this experience certain things in your teaching that you can change a bit...

In summary, Navigating the landscape is characterised by respondents becoming familiarized, and re-familiarized, with the program offered at the department from a broader perspective, for example the different teaching practices and progression between courses.

\section{Strengthening the role as a teacher}

The respondents reported that they became more aware of their own practice when preparing the observations, having colleagues in their classroom and engaging in the subsequent discussion. Consequently, Strengthening the role as a teacher is categorized by two components: seeing others in action, and gaining confidence.

Seeing others in action: Seeing others in action has two parts. In part, it relates to how teachers were inspired and excited when viewing others' teaching, and moreover, it relates to teachers becoming aware and reflective of their own practice. Many of the respondents reported being inspired watching their colleagues teaching and got ideas on how they could work with similar material in novel ways. Here, respondents reported that they started to reflect on how they engaged with individual students, or how the respondents treated students as a group in class activities. This was achieved by discussing their own classroom interaction, but also by observing the classroom activities of others. As such, the respondents reported that the CPR activities which formed the basis for the collective and collegial development work had a specific interpersonal dimension, even when it involved teachers observing each other's practices. This is shown in the two following quotes:

It was great to see other teachers in action. Not only watching what they did, but also becoming aware that I might address the same material, but in a different way. That gave me a chance to reflect on why I did things the way I did.

I think you will only be strengthened in your own convictions by looking at how others work. That makes you reflect about your own work, but in a different manner.

Having another teacher visit one's practice meant that one could engage in dialogue about one's own teaching. However, visiting another teacher's practice meant that 
the respondents could also learn about their own practice, through observation and dialogue. They reported getting a feel for whether they were doing things right in the eyes of their colleagues, and thus in relation to the teaching practice and the level at the department. This is shown in the two following quotes:

I usually give a response in one way, right. But my colleague did it in a completely different way, which I have never done. And then I thought: Why have I been doing things the same way all this time?

The conversation we had was very good for me as well, because I got feedback on things that I had not thought about previously, regarding structure and level. I believe, now, that I pitched the lesson too high.

Gaining confidence: The respondents reported that seeing others in action, and becoming aware of one's own practice, contributed to a growing sense of confidence. Their confidence in their own teaching practice grew and strengthened as a result of the observation activities they engaged in, but also thanks to the dialogue that took place after the observations. Elements of this sub-category could be seen in the following quotes:

I felt like the activity confirmed certain ideas I had about my own teaching, and I could also get some really concrete tips. I could also see that the changes I made as a result had an immediate effect on my own teaching.

I feel more confident with this group of students now, and I can see much more interaction between me and the students than before.

My colleagues are-just like me-ordinary mortals, not always super teachers.

In summary, Strengthening the role as a teacher is characterised by seeing others in practice, by becoming aware of one's own practice, but also by the growing sense of confidence felt after engaging in the CPR activities.

\section{Further collaboration}

This category consists of two parts, new ideas for course development and collaboration with new colleagues.

New ideas for course development: Preparing for dialogue with a colleague after observing their teaching was an integral part of the CPR activities. The respondents 
reported that this gave them an opportunity to frame and conceptualize their own practice, in terms of what intentions they had, how they expected the teaching to take place, what possible outcomes they could expect and so on. However, the outcome of the dialogues also resulted in reflections beyond the specific activity at hand. The respondents agreed that the activity generated all sorts of new and creative ideas about how to teach, simply by observing one another's teaching and having a conversation about this afterwards, following the focused approach of the CPR activities. In addition, the respondents spoke about several ideas for course development. In some cases, they had previously thought that they were alone in their beliefs about how specific courses would benefit from changes regarding content and mapping to other courses. Another point was that using the focused approach to classroom observation meant that they could address elements of teaching practice that may not be addressed in day-to-day conversation. This is shown in the following two quotes:

Yes, then afterwards we really got going, generating all sorts of new ideas, like, how could this content be made even easier and how would we be able to give more support, and maybe bring things up for discussion at that level.

I feel that if you have nothing like this project, you may not start talking, so you need to have this kind of project to start us talking to each other, that's when you get new ideas, so I think it's necessary to have this type of project.

Collaboration with new colleagues: Engaging in the CPR activities meant that some of the respondents got a chance to collaborate with colleagues with whom they had not yet been working closely, and in some cases, they found them to have the same views on pedagogical matters as themselves. They reported how the CPR activities had led them to initiate further collaboration on courses and teaching but also to establish partnerships for future projects. Moreover, the respondents said that participating in the CPR programme had enhanced their competence in teaching, and that they appreciated the possibility of collaborating in this kind of further training. They spoke enthusiastically about the activities they had already taken part in, as well as future project activities they planned to engage in. This is shown in the two following quotes:

I think it has opened new opportunities for cooperation. I'm going to start collaborating with some new colleagues, I probably wouldn't have done so otherwise. 
It could actually turn into something like a working team thing. The four of us could form a small team and work more closely together, both observing each other's teaching and supporting each other.

In summary, Further collaboration is characterised by the emergence of novel ideas about teaching and curriculum development and the informal establishment of new collegial partnerships for future projects.

\section{Frictions and tensions}

This category captures some of the frictions and tensions that were detected in both the focus-group interview data and the anonymous survey data. The CPR activities were formal activities that the respondents were given time to conduct. This meant that while respondents were free to approach any participating colleague to observe their classroom teaching, that person may not have been entirely comfortable with the experience. Some expressed nervousness prior to the observation, others chose not to use the formal instructions to structure the observations and dialogue. This is shown in the two following quotes:

The person in question said that they did not want me to focus on anything in particular. This made our conversation very difficult, as there was nothing to focus on. I thought giving a response was difficult.

Yes, in some cases it has been great and, in some cases, well, not so comfortable.

Some of the respondents acknowledged that, at first, giving feedback to a colleague felt a little awkward, but that each repeat of the CPR activities made things feel more comfortable. Moreover, the formal instructions of the CPR activities meant that any potential awkwardness could be encapsulated and blamed on the tool.

Sure, it was difficult in the beginning...but now I've done it three times I feel that next semester it will feel a lot better, and I think we will be able to offer better, more constructive feedback.

The participants reported nervousness when giving feedback to more experienced colleagues and experienced awkwardness when giving feedback to a colleague who did not seem particularly interested in receiving any feedback. 


\section{Discussion}

In the study we aimed to examine the outcome of a collegial peer review programme with a group of higher education teachers. Our study was set in a context where university teachers, once they have tenure, were rarely subject to external observation by managers. They were generally free to engage in their academic teaching as they see fit. Traditionally, this group of teachers would not have engaged in peer review of teaching practice, and this applies to many university teachers in the Nordic region. Our findings suggest that engagement in the CPR activities was perceived as worthwhile on both a personal and a collegial level. In accordance with previous research, the participants reported that the activities gave them an opportunity to break the isolation and strengthened their role as a teacher (Bell \& Cooper, 2013; Hendry et al., 2014). As a result of the structured format of the CPR activities, the respondents reported that they stepped outside their comfort zone, initiating collaboration with colleagues other than those they considered their personal friends. This broadening of the professional network was one of the most important aspects and outcomes of CPR activities; it also came as a result of a structured approach to collegial peer review. Our results also show that participating in the CPR activities led to ideas for further collaboration within the group. We believe that this contributes to a strengthening of professional relationships, enabling teachers to feel safer with their choices, but also strengthening them in their roles when moving to new workplaces (Bell \& Cooper, 2013; Shortland, 2010).

The results of this study resonate with previous research to the extent that faculty development programmes, with a collegial focus has shown positive impact on instructors' confidence in teaching (Poole et al., 2019). Trust between colleagues has also been identified as a central concept in relation to collegial faculty development initiatives (de Lange \& Wittek, 2020). However, apart from some frictions and tensions in a few feedback sessions where the observed teacher was not particularly interested in receiving any feedback, the respondents reported an overall positive perception of the CPR activities. This, we believe, is due to several reasons. We have therefore identified certain design features in our CPR program that might be necessary prerequisites for creating trust in peer review situations: There was a stated purpose of learning together in a non-judgmental way and reflecting on teaching and student learning. Participation was also entirely voluntary, with an opt-out possibility at any stage, and there was freedom to build partnerships as the teachers saw fit. The group of teachers that participated already constituted a group, in a sense, at their department, and they all knew each other to some extent as colleagues. They shared a common interest in each other's teaching that stretches beyond participation in a CPR project, since their teaching was part 
of the common objective of the unit. In our study, the request for the CPR activities came from the teachers themselves, and they were invited to partake in the process of creating the CPR activities. We believe that this bottom-up approach to peer review is important for creating commitment and establishing trust. We also conclude that having time set aside for engaging in peer review was important, to some extent, in incentivising the participants to engage in the project outlined here. At the same time, we argue that department leadership figures might consider the value of such initiatives as a way of fostering collegial peer development.

Some have argued that in the field of academic development work there is a propensity towards traditional, course-like interactions which may not provide space for the types of interaction we outline in the study (Bolander Laksov et al., 2020; McGrath, 2020). The respondents also stressed the importance of the longterm duration and iterative nature of the program, which made for gradual improvement in implementation. Here, we also acknowledge that, in general, many academic development courses run for a limited period of time, so in order to best utilise a peer review program, academic developers must also re-consider how academic development programs are offered in terms of time allocation.

Not only could we see personal and social impacts, the participants also reported a broader understanding of what the department's collective teaching practices looked like. This is shown in the category navigating the landscape, which overlaps somewhat with strengthening the role as a teacher, but where there is at least one important difference. While the focus of strengthening the role as a teacher was on personal development, in navigating the landscape teachers identified the value of CPR at a structural level, enabling them to see how different courses were linked and how progression between courses was intended to happen. The structured CPR activities provided an opportunity to have discussions about course development, course and program progression, and teaching activities that enhance student learning in different ways. We agree with Esterhazy et al. (2021) that constructive collegial faculty development interactions may be transformed into learning at individual level. Moreover, from an academic development perspective, these results may be interesting, since these types of reflection may be difficult to elicit from staff attending teacher training courses and workshops offered at academic development units with the individual academic in focus.

It is not uncommon for academics who attend CPD training to feel that they are unable to translate such training into practice (McGrath et al., 2019b). We suggest that CPR might enable stronger collective and collegial sharing and deeper reflection on teaching (Hammersley-Fletcher \& Orsmond, 2005). Sharing and discussing the insights of the teaching practice within a local context in relation to educational research may be a natural starting point for the individual's engagement in the development of scholarship of teaching and learning (Geertsema, 2016). Here 
also, academic developer units may play an important role. We know that there are a host of challenges and obstacles to initiating peer review processes, including lack of resources, overburdened faculty, lack of peer reviewer training, teacher anxiety or skepticism, scheduling conflicts and lack of a reliable reward system for faculty achievement (Fernandez \& Yu, 2007). However, to ease the process, academic developer units can organize specific peer review courses open to peers at a department, in which groups of teachers can explore peer review in a structured and supported fashion, enabling them to take risks in safe, non-judgmental environments. Here, we imagine academic developers could facilitate conversations between other significant actors (McGrath et al., 2016) and thereby 'strengthen elements of Scholarship by focusing on it as a means of developing high-quality teaching and improved student learning outcomes' (Geertsema, 2016, p. 132).

\section{Conclusion}

Today, collective, group-based participation in professional development does not generate the same currency as courses do. Consequently, academic development units may need to interact in different ways with university teachers, with a stronger focus on group-based collective practice and development work. Ideally, the collective and practice-oriented approach within peer review programs should complement traditional academic development work such as teacher-training courses and workshops with the individual academic in focus. Here, academic development units could play an important role in interacting with departments in collective and collegial peer development programs exemplified by the CPR activities of this case study.

\section{Limitations}

An important limitation is that our study is conducted in a setting with very high teacher autonomy and low elements of top-down control. Any transferability to settings where top-down managerial control is conducted using peer review may be difficult. Moreover, the respondents in this study were allocated time to participate; this means that the findings of this study may not be replicated in a setting where no time is allocated. 


\section{Author biographies}

Jeanna Wennerberg is a lecturer at the Department of Swedish and Multilingualism at Stockholm University, Sweden.

Cormac McGrath is associate professor of education and academic developer at the Centre for the advancement of University Teaching, Department of Education, Stockholm University. 


\section{References}

Baskerville, D., \& Goldblatt, H. (2009). Learning to be a critical friend: From professional indifference through challenge to unguarded conversations. Cambridge Journal of Education, 39(2), 205-221.

Bell, A., \& Thomson, K. (2018). Supporting peer observation of teaching: Collegiality, conversations, and autonomy. Innovations in Education and Teaching International, 55(3), 276-284.

Bell, M., \& Cooper, P. (2013). Peer observation of teaching in university departments: A framework for implementation. International Journal for Academic Development, 18(1), 60-73.

Bernstein, D. J. (2008). Peer review and evaluation of the intellectual work of teaching, Change: The Magazine of Higher Learning, 40(2), 48-51.

Bolander Laksov, K., Elmberger, A., Liljedahl, M., \& Björck, E. (2020). Shifting to team-based faculty development: A programme designed to facilitate change in medical education. Higher Education Research \& Development, Online first. https://doi.org/10.1080/07294360.2020.1841122

Boyer, E. L. (1990). Scholarship reconsidered: Priorities of the professoriate. Princeton: Carnegie Foundation for the Advancement of Teaching.

Braskamp L. A., \& Ory, J. C. (1994). Assessing faculty work: Enhancing individual and institutional performance. San Francisco: Jossey-Bass.

Byrne, J., Brown, H., \& Challen, D. (2010). Peer development as an alternative to peer observation: A tool to enhance professional development. International Journal for Academic Development, 15(3), 215-228.

Centra, J. A. (1993). Reflective faculty evaluation: Enhancing teaching and determining Faculty effectiveness. San Francisco: Jossey-Bass.

Chism, N. V. N., Holley, M., \& Harris, C. J. (2013). Researching the impact of educational development: Basis for informed practice. In J. E. Groccia, \& L. Cruz (Eds.), To improve the academy (pp.129-145). San Francisco: Jossey-Bass.

Costa, A. L., \& Kallick, B. (1993). Through the lens of a critical friend. Educational Leadership, 51(2) 49-51.

Dahlgren, L. O., Eriksson, B. E., Gyllenhammar, H., Korkeila, M., Sääf-Rothoff, A., Wernerson, A., \& Seeberger, A. (2006). To be and to have a critical friend in medical teaching. Medical Education, 40(1), 72-78.

de Lange, T., \& Wittek, A. L. (2018). Creating shared spaces: Developing teaching through peer supervision groups. Mind, Culture, and Activity, 25(4), 324339.

de Lange, T., \& Wittek, A. L. (2020). Analysing the constitution of trust in peerbased teacher mentoring groups: A sociocultural perspective. Teaching in 
Higher Education. Online first.

https://doi.org/10.1080/13562517.2020.1724936

Donnelly, R. (2007). Perceived impact of peer observation of teaching in higher education. International Journal of Teaching and Learning in Higher Education, 19(2), 117-129.

Elo, S., \& Kyngäs, H. (2008). The qualitative content analysis process. Journal of Advanced Nursing, 62(1), 107-115.

Engin, M. (2016). Enhancing the status of peer observation through the scholarship of teaching and learning. International Journal for Academic Development, 21(4), 377-382.

Esterhazy, R., de Lange, T., Bastiansen, S., \& Wittek, A. L. (2021). Moving beyond peer review of teaching: A conceptual framework for collegial faculty development. Review of Educational Research, 91(2), 237-271.

Fernandez, C. E., \& Yu, J. (2007). Peer review of teaching. Journal of Chiropractic Education, 21(2), 154-161.

Fileborn, B., Wood, M., \& Loughnan, C. (2020). Peer reviews of teaching as appreciative inquiry: learning from "the best" of our colleagues. Higher Education. Online first. https://doi.org/10.1007/s10734-020-00637-9

Geertsema, J. (2016). Academic development, SoTL and educational research. International Journal for Academic Development, 21(2), 122134.

Gosling, D. (2014). Collaborative peer-supported review of teaching. In J. Sachs \& M. Parsell (Eds.), Peer review of learning and teaching in higher education (pp. 13-31). Dordecht: Springer.

Hammersley-Fletcher, L., \& Orsmond, P. (2005). Reflecting on reflective practices within peer observation. Studies in Higher Education, 30(2), 213-224.

Handal, G. (1999). Consultation using critical friends. New Directions for Teaching and Learning, 1999(79), 59-70.

Handal, G. (2007). Identities of academic developers: Critical friends in the academy? In R. Barnett, \& R. Napoli (Eds.), Changing identities in higher education (pp. 69-82). Abingdon: Routledge.

Hendry, G. D., Bell, A., \& Thomson, K. (2014). Learning by observing a peer's teaching situation. International Journal for Academic Development, 19(4), 318-329.

Hsieh, H.-F., \& Shannon, S. E. (2005). Three approaches to qualitative content analysis. Qualitative Health Research, 15(9), 1277-1288.

Huber, M. T., \& Hutchings, P. (2006) Building the teaching commons. Change: The Magazine of Higher Learning, 38(3), 24-31.

Hutchings, P. (Ed.) (1995). From idea to prototype: The peer review of teaching. Sterling, VA: Stylus. 
Hutchings, P. (Ed.) (1996). Making teaching community property: A menu for peer collaboration and peer review. Sterling, VA: Stylus.

Hutchings, P., Huber, M. T., \& Ciccone, A. (2011). The Scholarship of Teaching and Learning Reconsidered. San Francisco: Jossey-Bass.

Kember, D., Ha, T.-S., Lam, B.-H., Lee, A., NG, S., Yan, L., \& Yum, J. C. K. (1997). The diverse role of the critical friend in supporting educational action research projects. Educational Action Research, 5(3), 463-481.

Kreber, C. (2002). Teaching excellence, teaching expertise, and the scholarship of teaching. Innovative Higher Education, 27(1), 5-23.

McGrath, C. (2020). Academic developers as brokers of change: insights from a research project on change practice and agency. International Journal for Academic Development, 25(2), 94-106.

https://doi.org/10.1080/1360144X.2019.1665524

McGrath, C., Barman, L., Stenfors-Hayes, T., Roxå, T., Silén, C., \& Laksov, K. B. (2016). The ebb and flow of educational change: Change agents as negotiators of change. Teaching \& Learning Inquiry, 4(2), 1-14.

McGrath, C., Palmgren, P. J., \& Liljedahl, M. (2019a). Twelve tips for conducting qualitative research interviews. Medical Teacher, 41(9), 1002-1006.

McGrath, C., Roxå, T., \& Bolander Laksov, K. (2019b). Change in a culture of collegiality and consensus-seeking. A double-edged sword. Higher Education Research \& Development, 38(5), 1001-1014. https://doi.org/10.1080/07294360.2019.1603203

Myatt, P., Gannaway, D., Chia, I., Fraser, K., \& McDonald, J. (2018). Reflecting on institutional support for SoTL engagement: Developing a conceptual framework. International Journal for Academic Development, 23(2), 147160.

Poole, G., Iqbal, I., \& Verwoord, R. (2019). Small significant networks as birds of a feather. International Journal for Academic Development, 24(1), 61-72.

Sell, G., \& Chism, N. (1988). Assessing teaching effectiveness for promotion and tenure: a compendium of reference materials. Columbus Ohio State University Center for Teaching Excellence.

Shortland, S. (2010). Feedback within peer observation: Continuing professional development and unexpected consequences. Innovations in Education and Teaching International, 47(3), 295-304.

Söderhjelm, T., Björklund, C., Sandahl, C., \& BolanderLaksov, K. (2018). Academic leadership: Management of groups or leadership of teams? A multiple-case study on designing and implementing a team-based development programme for academic leadership. Studies in Higher Education, 43(2), 201-216.

Tierney, A. M., Aidulis, D., Park, D., \& Clark, K. (2020). Supporting SoTL 
Development through Communities of Practice. Teaching \& Learning Inquiry, 8(2), 32-52.

Trigwell, K., \& Shale, S. (2004). Student learning and the scholarship of university teaching. Studies in Higher Education, 29(4), 523-536.

van der Rijst, R., Baggen, Y., \& Sjoer, E. (2019). University teachers' learning paths during technological innovation in education. International Journal for Academic Development, 24(1), 7-20.

Özek, Y. H., Edgren, G., \& Jandér, K. (2012). Implementing the critical friend method for peer feedback among teaching librarians in an academic setting. Evidence Based Library and Information Practice, 7(4), 68-81. 